\title{
Facebook for Facing Dementia
}

\section{Tanjir Rashid Soron*}

Cyberpsychology Research and Consultation Center, 17/D/1 Mogbazar, 1217, Bangladesh

${ }^{*}$ Corresponding author: Tanjir Rashid Soron, Principal Investigator and Founder, Cyberpsychology Research and Consultation Center, 17/D/1 Mogbazar, 1217, Bangladesh, Tel: + 88001718827138; Fax: 1718827138; E-mail: tanjirsoron@yahoo.com

Received date: Sep 8, 2016; Accepted date: Sep 9, 2016; Published date: Sep 12, 2016

Copyright: (C) 2016 Saron TR. This is an open-access article distributed under the terms of the Creative Commons Attribution License, which permits unrestricted use, distribution, and reproduction in any medium, provided the original author and source are credited.

Citation: Saron TR. Facebook for facing Dementia. Clin Psychiatry. 2016, 2:3.

\section{Editorial}

Facebook is bridging the generations. A large portion of elderly people logs in Facebook first time in their life after the age of 65 year with an impaired memory. This paper focused on a few ideas that can help in prevention and management of dementia. Facebook is helpful in enhancing social stimulation and interaction. This is one of the key elements of nonpharmacological interventions for dementia. The photos or videos uploaded in Facebook may augment the memories of the persons and the events and thus it can halt the process of forgetting that persons or events. The senior people can interact with comments, likes and share options of Facebook to remain socially connected. Grandparents and parents are left behind alone. They need someone to talk. Moreover, a unique Facebook group for dementia will encourage sharing of information and expression of their views. The group members can motivate one another to perform daily activities on schedule by poking or sending regular message in their Facebook inbox. They will respond after completing each scheduled task to other. The psychiatrist, caregivers and other group members can follow and provide feedback of their activities continuously. It can be a source of data of their behavior also. To provide music therapy Facebook can automatically play especially dedicated song or music for them at a regular interval. Different cognitive enhancing games designed in the Facebook can be useful for them in the early stage. Moreover, the Facebook location system will help us to find out if our dearest person unfortunately gets lost. However, in case of severe cognitive impairment, the seniors may feel difficulties in using Facebook. The Facebook can be a new cost effective arsenal for combating dementia in the initial stages. Future researchers can consider evaluating the impact of Facebook in these domains. 